\title{
Editorial
}

\section{Models, Methods, and Applications of Dynamics and Control in Engineering Sciences: State of the Art}

\author{
José Manoel Balthazar, ${ }^{1}$ Paulo Batista Gonçalves, ${ }^{2}$ \\ Stefano Lenci, ${ }^{3}$ and Yuri Vladimirovich Mikhlin ${ }^{4}$ \\ ${ }^{1}$ Universidade Estadual Paulista (UNESP), Rio Claro, SP, Brazil \\ ${ }^{2}$ Catholic University, Rio de Janeiro, Brazil \\ ${ }^{3}$ Polytechnic University of Marche, Ancona, Italy \\ ${ }^{4}$ National Technical University, Kharkov, Ukraine \\ Correspondence should be addressed to José Manoel Balthazar, jmbaltha@rc.unesp.br
}

Received 22 June 2010; Accepted 22 June 2010

Copyright $(\odot 2010$ José Manoel Balthazar et al. This is an open access article distributed under the Creative Commons Attribution License, which permits unrestricted use, distribution, and reproduction in any medium, provided the original work is properly cited.

The goal of this special issue of Mathematical Problems in Engineering (MPE) is to present papers, containing complete reviews on modern dynamics models, available in the current literature, classify them, and discuss their applications and limitations. It was assumed to consider papers containing a discussion on appropriate models and control criteria and on various applications on Engineering and Sciences and suggest directions for further works. The critical reviews, a description of open problems, and future developments were hailed. 93 papers were presented for this issue, and 21 of them were accepted. There are 9 review papers and 12 research articles. In particular, there are reviews on the feedback designs for linear descriptors, modeling of ship dynamics, continuous models for discrete media, applications of fractional calculus in engineering, nonlinear fault tolerant control, simulation of a target tracking system with backlash compensation, dynamics of furuta's pendulum, and identification approaches for discrete event systems. One review is devoted to advances in structural control of civil engineering in China. There are 8 articles which are devoted to investigations in nonlinear dynamics; 8 articles are devoted to the control problems; 4 articles treat numerical approaches and problems of simulation. The majority of accepted articles contains modeling, as well as analytical and/or numerical investigations. The contents of the 9 reviews papers are briefly summarized in the following.

(1) "Modeling of ship roll dynamics and its coupling with heave and pitch," by R. A. Ibrahim and I. M. Grace. An overview of the roll dynamic stability under random sea waves has been presented in terms of the sample stability condition and response statistical moments. 
(2) "Some applications of fractional calculus in engineering," by J. A. T. Machado, et al. This article presents several case studies on the implementation of FC-based models and control systems, with the advantages of using the FC theory in different areas of science and engineering being demonstrated.

(3) "Improved continuous models for discrete media," by I. V. Andrianov et al. This paper focuses on continuous models derived from a discrete microstructure. Various continualization procedures that take into account the nonlocal interaction between variables of the discrete media are analysed.

(4) "Furuta's pendulum: a conservative nonlinear model for theory and practise," by J. Á. Acosta. A detailed dynamical model of the available laboratory Furuta's pendulum is provided. A survey of all the nonlinear controllers designed with that quasiconservative model and successfully tested through experiments is also reported.

(5) "A comparative analysis of recent identification approaches for discrete event systems," by A. P. Estrada-Vargas et al. This paper overviews identification approaches of DES found in the literature and then it provides a comparative analysis of three recent and innovative contributions.

(6) "A survey of some recent results on nonlinear fault tolerant control," by M. Benosman. This paper presents a survey of some of the results obtained last years on nonlinear Fault tolerant control (NFTC).

(7) "Advances in structural control in civil engineering in china," by Hongnan Li and Linsheng Huo. The aim of this paper is to review a state of the art of researches and applications of structural control in civil engineering in China. It includes the passive control, active control, hybrid control and semiactive control.

(8) "Time domain simulation of a target tracking system with backlash compensation," by M. Gruzman et al. This paper presents the modeling and control of a target tracking system assembled into a moving body. Special attention is given to the problems caused by backlash in gear transmission.

(9) "Robust state-derivative feedback LMI-based designs for linear descriptor systems," by F. A. Faria et al. Necessary and sufficient stability conditions based on LMI for state-derivative feedback of linear descriptor systems are presented. The proposed methods are LMI-based designs that, when feasible, can be efficiently solved by convex programming techniques.

The contents on the research articles are somehow more spread and are summarized in the following.

(10) "Applied model-based analysis and synthesis for the dynamics, guidance, and control of an autonomous undersea vehicle," by Kangsoo Kim and Tamaki Ura. In this article, a model-based analysis and synthesis to the following three research fields in AUV(Autonomous Undersea Vehicle) design and development have been presented: dynamic system modelling of an AUV, motion control design and tracking control application, and an optimal guidance of an AUV in environmental disturbances. 
(11) "Control of limit cycle oscillations of a two-dimensional aeroelastic system," by M. Ghommem et al. Linear and nonlinear controls are implemented on a rigid airfoil undergoing pitch and plunge motions. The method of multiple scales is applied to the governing system of equations to derive the normal form of the Hopf bifurcation near the flutter onset. On the other hand, the nonlinear control can be efficiently implemented to convert subcritical to supercritical Hopf bifurcations and to significantly reduce LCO amplitudes.

(12) "Investigation of aeroelastic mode distribution for aircraft wing model in subsonic air flow," by Marianna A. Shubov et al. The presented paper is concerned with numerical investigation of two problems arising in the area of theoretical aeroelasticity. Namely, it has been shown that analytical formulas representing the asymptotical distribution of aeroelastic modes for a specific aircraft wing model can be used by practitioners.

(13) "Nonlinear and dynamic aerodynamic models for commercial transport aircraft with adverse weather effects," by Ray C. Chang et al. This paper presents a numerical modeling method based on a fuzzy-logic algorithm which is presented to estimate the aerodynamic models for a twin-jet transport by using the flight data from the flight data recorder (FDR).

(14) "Limiting phase trajectories and resonance energy transfer in a system of two coupled oscillators," by L. I. Manevitch et al. In this paper, the authors have extended the concept of the limiting phase trajectories (LPTs) to dissipative oscillatory systems. Using this concept, they have constructed an approximate solution describing the maximum energy exchange between coupled oscillators.

(15) "A wavelet interpolation galerkin method for the simulation of MEMS devices under the effect of squeeze film damping," by $\mathrm{Pu} \mathrm{Li}$ and Yuming Fang. This paper presents a new wavelet interpolation Galerkin method for the numerical simulation of MEMS devices under the effect of squeeze film damping. Simulation results show that the results of the wavelet interpolation Galerkin method match the experimental data better than that of the finite difference method by about $10 \%$.

(16) "Modeling and fuzzy PDC control and its application to an oscillatory TLP structure," by Cheng-Wu Chen. An analytical solution is derived to describe the wave-induced flow field and surge motion of a deformable platform structure controlled with fuzzy controllers in an oceanic environment. In the controller design procedure, a parallel distributed compensation (PDC) scheme is utilized to construct a global fuzzy logic controller by blending all local state feedback controllers.

(17) "Adaptive fuzzy tracking control for a permanent magnet synchronous motor via backstepping approach," by Jinpeng Yu et al. Based on adaptive fuzzy control approach and backstepping technique, an adaptive fuzzy control scheme is proposed to control a permanent magnet synchronous motor. The proposed controllers guarantee that the tracking error converges to a small neighborhood of the origin and all the closed-loop signals are bounded. Simulation results illustrate an effectiveness of the presented method.

(18) "Design for motor controller in hybrid electric vehicle based on vector frequency conversion technology," by Jing Lian et al. This paper carries on the research of motor control technology of application HEV, designs HEV motor controller based on vector frequency conversion technology, and completes the controller's software and 
hardware design. In accordance with the characteristics of the HEV electromagnetic interference source, propagation path, and CAN bus communication, this paper proposes the corresponding antijamming measures, which greatly improves the antijamming ability of the CAN bus system and controller working stability.

(19) "Biologically inspired robotic arm control using an artificial neural oscillator," by Woosung Yang et al. The authors have presented a control scheme for technically achieving a biologically inspired self-adapting robotic motion. In contrast to existing works that were only capable of rhythmic pattern generation for simple tasks, the presented approach allows the robot arm to precisely trace a trajectory correctly through entrainment. With this, the proposed method is verified through more complex behaviors of the real robot arm under unknown environmental changes.

(20) "Shape sensitivity analysis in flow models using a finite-difference approach," by I. Akhtar et al. The authors consider flows past an elliptic cylinder with varying thickness ratios. Shape sensitivities (derivatives of flow variables with respect to thickness ratio) computed by finite-difference approximations are used to compute the POD sensitivity vectors. Numerical studies test shows the accuracy of the new bases to represent flow solutions over a range of parameter values.

(21) "Investigations on actuator dynamics through theoretical and finite element approach," by Somashekhar S. Hiremath and M. Singaperumal. This paper gives a new approach for modeling the fluid-structure interaction of servovalve component-actuator. The analyzed valve is a precision flow control valve-jet pipe electrohydraulic servovalve. The positioning of an actuator depends upon the flow rate from control ports, in turn depends on the spool position. Theoretical investigation is made for No-Load condition and Load condition for an actuator. These are used in finite element modeling of an actuator. The fluid-structure-interaction (FSI) is established between the piston and the fluid cavities at the piston end. The fluid cavities were modeled with special purpose hydrostatic fluid elements while the piston is modeled with brick elements.

As a final remark, we want to thank all the authors for their contributions and we hope that the present special issue can be useful in the development of the research in the area on nonlinear dynamics and control.

Jose Manoel Balthazar

Paulo Batista Gonçalves

Stefano Lenci

Yuri Vladimirovich Mikhlin 


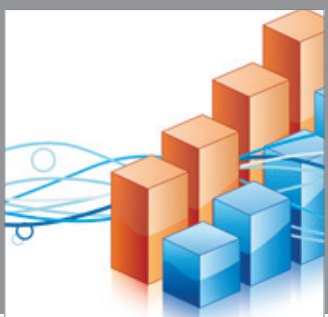

Advances in

Operations Research

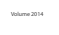

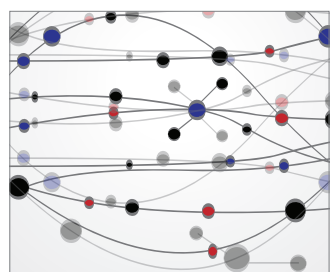

\section{The Scientific} World Journal
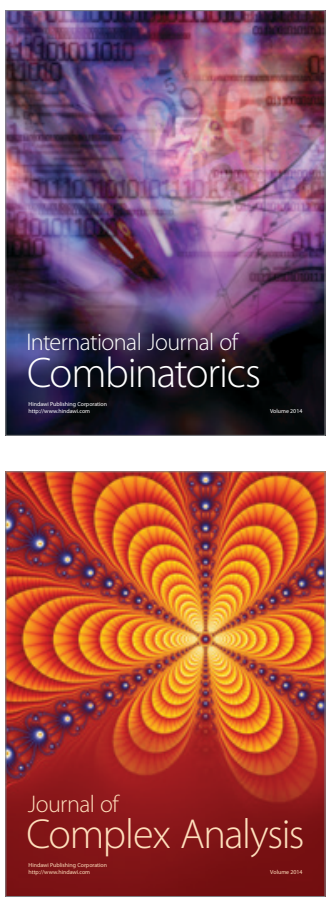

International Journal of

Mathematics and

Mathematical

Sciences
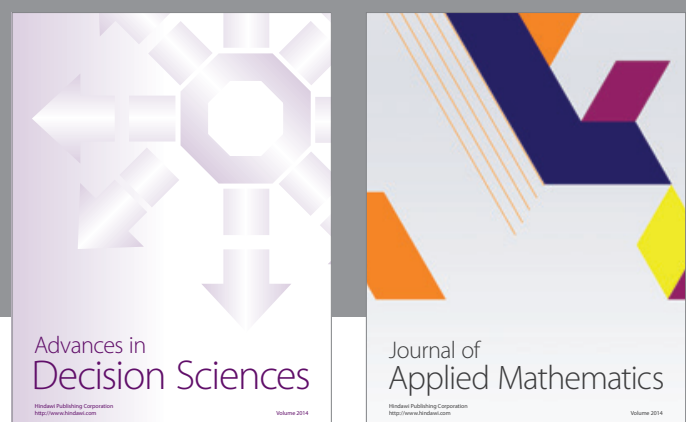

Journal of

Applied Mathematics
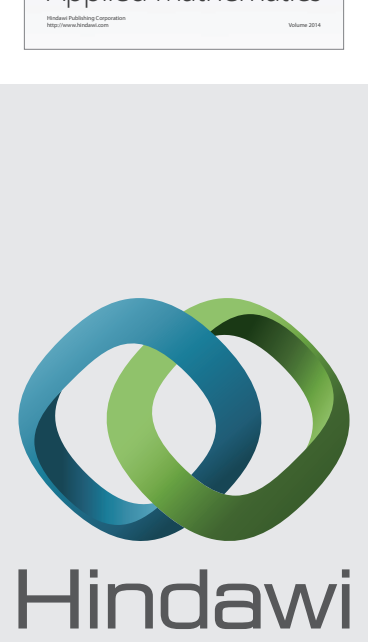

Submit your manuscripts at http://www.hindawi.com
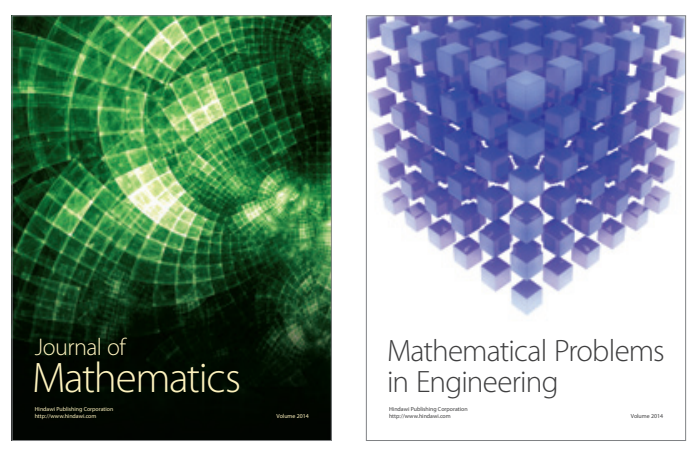

Mathematical Problems in Engineering
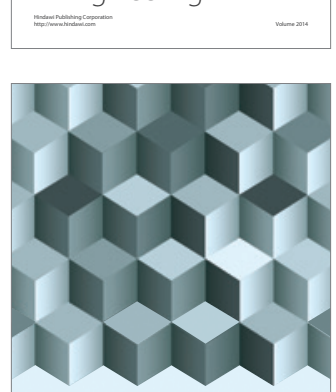

Journal of

Function Spaces
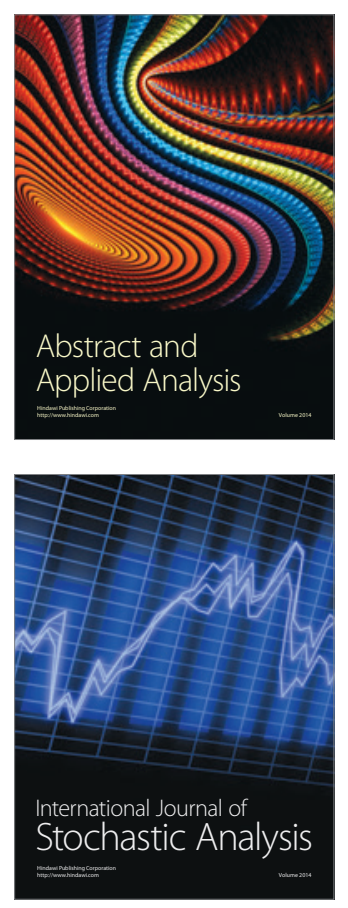

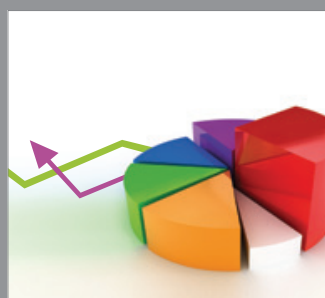

ournal of

Probability and Statistics

Promensencen
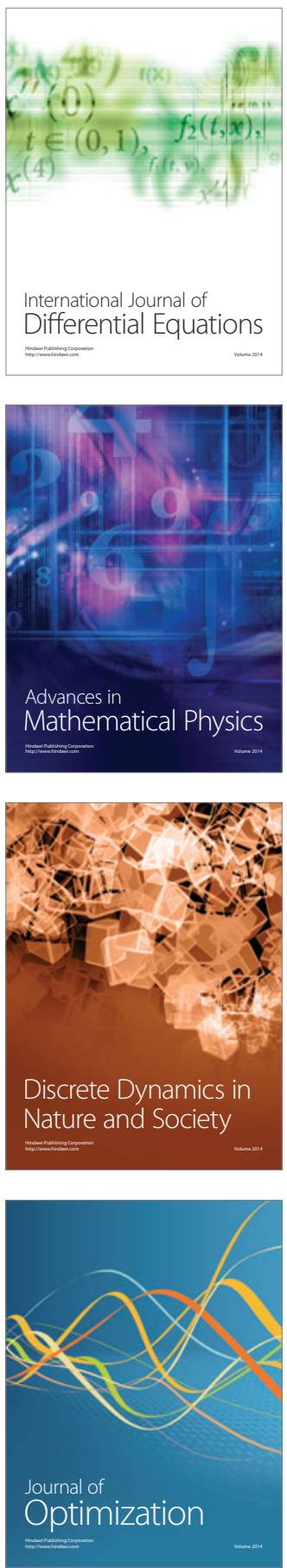